\title{
Retrospective analysis of oral peripheral nerve sheath tumors in Brazilians
}

\section{Juliana Tito Salla(a) Aline Cristina Batista Rodrigues Johann ${ }^{(b)}$ \\ Bruna Gonçalves Garcia(a) Maria Cássia Ferreira Aguiar(c) Ricardo Alves Mesquita ${ }^{(c)}$}

(a)DDS; (b)MSc; (c) PhD, Professor - Department of Oral Surgery, Medicine and Pathology, School of Dentistry, Federal University of Minas Gerais, MG, Brazil.
Corresponding author: Ricardo Alves Mesquita

Universidade Federal de Minas Gerais

Faculdade de Odontologia

Av. Antônio Carlos, 6667, sala 3204

- Pampulha

Belo Horizonte - MG - Brazil

CEP: 31270-901

E-mail: ramesquita@ufmg.br
Abstract: Traumatic neuroma, neurofibroma, neurilemmoma, palisaded encapsulated neuroma and malignant peripheral nerve sheath tumor (MPNST) are peripheral nerve sheath tumors and present neural origin. The goal of this study was to describe the epidemiological data of oral peripheral nerve sheath tumors in a sample of the Brazilian population. Biopsies requested from the Oral Pathology Service, School of Dentistry, Federal University of Minas Gerais (MG, Brazil), between 1966 and 2006 were evaluated. Lesions diagnosed as peripheral nerve sheath tumors were submitted to morphologic and to immunohistochemical analyses. All cases were immunopositive to the S-100 protein. Thirty-five oral peripheral nerve sheath tumors were found, representing $0.16 \%$ of all lesions archived in the Oral Pathology Service. Traumatic neuroma (15 cases) most frequently affected the mental foramen. Solitary neurofibroma (10 cases) was more frequently observed in the palate. Neurofibroma associated with neurofibromatosis type I ( 2 cases) was observed in the gingival and alveolar mucosa. Neurilemmoma (4 cases) was more commonly observed in the buccal mucosa. Malignant peripheral nerve sheath tumors (3 cases) occurred in the mandible, palate, and tongue. Palisaded encapsulated neuroma (1 case) occurred in the buccal mucosa. The data confirmed that oral peripheral nerve sheath tumors are uncommon in the oral region, with some lesions presenting a predilection for a specific gender or site. This study may be useful in clinical dentistry and oral pathology practice and may be used as baseline data regarding oral peripheral nerve sheath tumors in other populations.

Descriptors: Neuroma; Neurofibroma; Nerve sheath neoplasms; Mouth; Epidemiology. 


\section{Introduction}

Peripheral nerve sheath tumors may be classified in benign and malignant. The first category includes traumatic neuroma, neurofibroma, neurilemmoma, and palisaded encapsulated neuroma (PEN) whereas the second category consists of malignant peripheral nerve sheath tumor (MPNST). These tumors share a common neural origin but present microscopic and clinical heterogeneity. ${ }^{1,2}$

The traumatic neuroma is a non-neoplastic lesion characterized by the proliferation of schwann cells and nerve fibers that arise following injury to a nerve. ${ }^{3-5}$ Jones, Franklin ${ }^{6}$ (2006), in a series of 44,007 oral and maxillofacial pathologies, observed that $0.34 \%$ of the cases were of traumatic neuroma. In studies of oral peripheral nerve sheath tumor cases, the following frequencies of traumatic neuroma were observed: $16 \%{ }^{7}$ and $29.9 \% .^{1}$

Neurofibroma is a circumscribed but non-encapsulated tumor consisting of a mixture of schwann cells, perineurial cells, and endoneurial fibroblasts. ${ }^{1,2,4}$ Jones, Franklin ${ }^{6}$ (2006) found the frequency of this lesion to be $0.43 \%$. In oral peripheral nerve sheath tumors, the frequencies identified for neurofibroma were $20.8 \%{ }^{1}$ and $32 \% .^{7}$

Neurilemmoma is an encapsulated neoplasm composed of schwann cells arranged in two patterns: Antoni type A and Antoni type B. ${ }^{1,5}$ Although they can occur in any region, 25 to $48 \%$ of the lesions occur in the head and neck region. ${ }^{8}$ One study regarding oral and maxillofacial pathologies reported a $0.1 \%$ frequency for this lesion. ${ }^{6}$ The frequencies of $16.9 \%^{1}$ and $22 \%{ }^{7}$ for neurilemmoma were recorded in studies of the oral peripheral nerve sheath tumors.

PEN is characterized by a bundle of nerves interposed to schwann cells, which characteristically aggregate in palisades. ${ }^{1,2,9}$ This is a well-circumscribed tumor that represents $0.05 \%$ of the oral biopsy specimens. ${ }^{10}$ The frequency of PEN found in a study of oral peripheral nerve sheath tumors was $20.8 \%{ }^{1}$

MPNSTs are spindle-cell sarcomas that arise from nerve, neurofibroma, neurilemmoma, or tissue containing nerves. ${ }^{2,11}$ Although 8 to $16 \%$ of MPNSTs develop in the head and neck region, this lesion is extremely rare in the oral cavity. ${ }^{12} \mathrm{~A}$ simi- lar frequency $(8 \%)$ of this lesion was described in a study on oral peripheral nerve sheath tumors. ${ }^{7}$

Epidemiologic studies on oral lesions have been conducted, being important sources of knowledge and contributing to the practice of clinical dentistry and oral pathology. ${ }^{13,14}$ However, few authors have assessed the epidemiological features of oral peripheral nerve sheath tumors to date..$^{1,5-7}$ The aim of this paper was to describe the epidemiological data on the peripheral nerve sheath tumors recorded in the archives of the Oral Pathology Service, School of Dentistry, Federal University of Minas Gerais (UFMG), MG, Brazil.

\section{Material and Methods}

The protocol of this study was approved by the Committee for Bioethics in Research, UFMG (016/03).

All files regarding oral peripheral nerve sheath tumors submitted to the Oral Pathology Service, School of Dentistry, UFMG (FO-UFMG) from 1966 to 2006 were reviewed. These files were classified in accordance with histological and immunohistochemical criteria. Histological sections stained with haematoxilin and eosin were analyzed using an optic microscope (Axiostar 1122-110, Carl Zeiss, Oberkochen, Baden-Wüttemberg, Germany). Patient clinical data and lesion location were recorded. The histological criteria used to classify the peripheral nerve sheath tumors were in accordance with Enzinger, Weiss ${ }^{2}$ (1995).

Immunohistochemistry staining to detect S-100 proteins was performed for all lesions using the standard streptavidin-biotin-peroxidase method on deparaffinized tissue sections. The sections were incubated with an S-100 primary antibody (Z0311, Dako Corporation ${ }^{\circledR}$ Carpinteria, CA, USA) at a 1:700 dilution for 18 hours at $4^{\circ} \mathrm{C}$. Mayers hematoxilin was used as a counterstain. All lesions were positive for S-100. In MPNST lesions, immunohistochemistry staining for AE1/AE3 (M3515, Dako

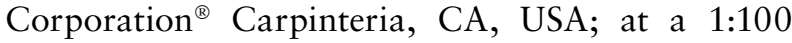
dilution), HHF35 (M0635, Dako Corporation ${ }^{\circledR}$ Carpinteria, CA, USA; at a 1:100 dilution), and $\alpha$ smooth muscle actin (M0851, Dako Corporation ${ }^{\circledR}$ Carpinteria, CA, USA; at a 1:50 dilution) were also 
performed. An antigen retrieval was also performed using a $10 \mathrm{mM}$ citrate buffer $(\mathrm{pH}=6.0,30 \mathrm{~min}$ at $98^{\circ} \mathrm{C}$ ) in stains testing AE1/AE3 and $\alpha$ - smooth muscle actin. The primary antibody was also incubated for 18 hours at $4^{\circ} \mathrm{C}$. MPNST showed a negative stain for AE1/AE3, HHF35, and $\alpha$ - smooth muscle actin.

\section{Results}

Oral peripheral nerve sheath tumors represented $35(0.2 \%)$ of 21,476 specimens biopsied from 1966 to 2006 in the Oral Pathology Service, FO-UFMG. The cases diagnosed included 15 (42.9\%) traumatic neuromas, $10(28.6 \%)$ solitary neurofibromas, 2 (5.6\%) neurofibromas associated with neurofibromatosis type I, $4(11.4 \%)$ neurilemmomas, 1 (2.9\%) PEN, and $3(8.6 \%)$ MPNSTs. The clinical data are presented in Table 1.

The neurilemmomas presented $50 \%$ of the lesions composed of Antoni type A pattern and 50\% composed of a mixture of both patterns, Antoni type A and type B. All of these tumors were encapsulated.

\section{Discussion}

The oral peripheral nerve sheath tumors were considered rare as they occurred in only 35 cases among 21,476 biopsied lesions from FO-UFMG, representing $0.2 \%$ of all lesions. Studies regarding oral peripheral nerve sheath tumors reported the frequencies of these lesions, without immunohistochemical evaluation. ${ }^{6,7}$ However, Chrysomali et al. ${ }^{1}$ (1997) evaluated 77 oral peripheral nerve sheath tumors using immunohistochemistry to detect the S-100 protein, CD57, epithelial membrane antigen (EMA), factor XIIIa, CD34, CD68, and collagen IV. Likewise, Magnusson ${ }^{10}$ (1996) studied 12 cases of oral PEN evaluating the expression of S-100, neurofilament and EMA.

Used as an auxiliary method in the diagnosis of the peripheral nerve sheath tumors, the most common immunohistochemical markers described in the literature include: S-100, CD34, and EMA. In the present study, S-100 was used because it represented an easy marker, has been widely used in the identification of schwann cells, and aids greatly in the diagnostic process. ${ }^{1,15-17}$ The neural origin of all lesions of this study was confirmed by the immuno-

Table 1 - Clinical data of oral peripheral nerve sheath tumors (FOUFMG, 1966 - 2006).

\begin{tabular}{|c|c|c|c|}
\hline Tumor & $\begin{array}{l}\text { Mean age } \\
\text { (Range) }\end{array}$ & $\begin{array}{l}\text { Gender } \\
\text { (cases) }\end{array}$ & Sites \\
\hline Traumatic neuroma $(n=15)$ & $\begin{array}{c}33.5 \\
(10-80)\end{array}$ & $\begin{array}{l}M(5) \\
F(10)\end{array}$ & $\begin{array}{l}\text { Mental foramen (6) } \\
\text { Lower lip (3) } \\
\text { Buccal mucosa (2) } \\
\text { Tongue (2) } \\
\text { Hard/soft palate (2) }\end{array}$ \\
\hline Solitary neurofibroma $(n=10)$ & $\begin{array}{c}31.2 \\
(9-50)\end{array}$ & $\begin{array}{l}M(1) \\
F(9)\end{array}$ & $\begin{array}{l}\text { Hard palate (4) } \\
\text { Gingiva, anterior region (2) } \\
\text { Tongue (2) } \\
\text { Mandibular symphysis (1) } \\
\text { Lower lip (1) }\end{array}$ \\
\hline $\begin{array}{l}\text { Neurofibroma associated with } \\
\text { neurofibromatosis type } 1(n=2)\end{array}$ & $\begin{array}{c}23.0 \\
(10-36)\end{array}$ & $\begin{array}{l}M(1) \\
F(1)\end{array}$ & $\begin{array}{l}\text { Gingiva, anterior region (1) } \\
\text { Alveolar Mucosa (1) }\end{array}$ \\
\hline Neurilemmoma $(n=4)$ & $\begin{array}{c}23.7 \\
(12-31)\end{array}$ & $\begin{array}{l}M(0) \\
F(4)\end{array}$ & $\begin{array}{l}\text { Buccal mucosa (2) } \\
\text { Hard palate (1) } \\
\text { Tongue (1) }\end{array}$ \\
\hline MPNST $(n=3)$ & $\begin{array}{c}45.0 \\
(37-61)\end{array}$ & $\begin{array}{l}M(3) \\
F(0)\end{array}$ & $\begin{array}{l}\text { Mandible, anterior region (1) } \\
\text { Hard palate (1) } \\
\text { Tongue (1) }\end{array}$ \\
\hline $\operatorname{PEN}(n=1)$ & $*$ & $\begin{array}{l}M(0) \\
F(1)\end{array}$ & Buccal mucosa (1) \\
\hline
\end{tabular}

F: Female; M: Male; *: no data; MPNST: malignant peripheral nerve sheath tumor, PEN: palisaded encapsulated neuroma. 
histochemical tests for the S-100 protein, since all samples were positive to this antigen. In $100 \%$ of the cases of traumatic neuroma, schwann cells within the nerve fascicles were immunoreactive toward $\mathrm{S}-100$. This is also reported in the findings from Chrysomali et al. ${ }^{1}$ (1997) and Weiss et al. ${ }^{17}$ (1983). The positive stain for S-100 was also observed in $100 \%$ of the neurofibroma cases, which is a rate similar to that found in the literature. ${ }^{1,15,17}$ However, as indicated by Enzinger, Weiss ${ }^{2}$ (1995), the S-100 immunostain in neurofibroma is not as notable as in neurilemmoma. In the present study, all cases of neurilemmoma also showed positive staining for S100, which is also reported by Hirose et al. ${ }^{15}$ (2003). However, Weiss et al. ${ }^{17}$ (1983) found positive immunostains for S-100 in 91\% of the cases of neurilemmoma, whereas Chrysomali et al. ${ }^{1}$ (1997) observed this in only $31 \%$ of the cases. The case of PEN, on the other hand, stained positively for S-100. Argenyi $^{3}$ (1990) found $100 \%$ of the cases to be positive for S-100, in contrast with Chrysomali et al. ${ }^{1}$ (1997) who found $25 \%$ of the cases to be immunopositive. S-100 immunostaining was observed in $100 \%$ of the MPNST cases presented in this study, however, the literature described this as varying from 50 to $90 \%$ of the cases. ${ }^{2,17}$

Traumatic neuroma is most frequently located in the tongue, lips, ${ }^{1,18}$ and mental nerve area. ${ }^{5}$ We also found the same neuroma in areas including the buccal mucosa and palate. These tumors affected adults and children from 10 to 80 years of age, with a mean age of 33.5, which is in accordance with Chrysomali et al. ${ }^{1}$ (1997). The female preponderance noticed in this study is also reported in the findings from Chrysomali et al. ${ }^{1}$ (1997).

In the solitary neurofibroma, the most common sites found by Shklar, Meyer ${ }^{7}$ (1963) and Wright, Jackson $^{5}$ (1980) were the tongue, the palate, the buccal mucosa and the floor of the mouth. In contrast, the main site observed by Ellis et al. ${ }^{19}$ (1977) was the posterior region of the mandible, while Chrysomali et al. ${ }^{1}$ (1997) reported it in the alveolar mucosa and the palate. In the present study, the palate and the gingiva were the most frequently intraoral and paraoral tissues involved. Also, one case located in the mandibular symphysis was observed in this study. Like- wise, neurofibromas of the jaw have been described in the literature..$^{20,21}$ As to neurofibromas, it was observed that these lesions affected adults and children from 9 to 50 years of age, with a mean age of 31.2, which is in accordance with the literature. ${ }^{2,5,11,19}$ As observed by other authors, ${ }^{1,5,19}$ our study also pointed out a female preponderance. However, Enzinger, Weiss $^{2}$ (1995) and Pilavaki et al. ${ }^{11}$ (2004) related no gender dominance to this lesion.

Neurofibromatosis type I is a disorder characterized by the presence of two or more of the following findings: six or more "café au lait" macules (> $5 \mathrm{~mm}$ in diameter in puberty and $>15 \mathrm{~mm}$ in postpuberty patients), two or more neurofibromas of any type or one plexiform, freckling in the axillary or inguinal regions, optic glioma, two or more "Lish" nodules, and a distinctive osseous lesion. ${ }^{22}$ Two cases of neurofibroma were associated with neurofibromatosis type I. Association of the oral neurofibroma and neurofibromatosis type $\mathrm{I}$ is uncommon. ${ }^{5}$ The lesions in the oral soft tissues have been identified with a prevalence of less than $10 \%,{ }^{23} 26 \%{ }^{20}$ and up to $72 \%$ of patients. ${ }^{21}$ In addition, neurofibromas associated with neurofibromatosis type I are most frequently found in the tongue, but have also been identified in the gingiva, the alveolar mucosa, the palate, the buccal mucosa, the lip, the floor of the mouth, and the buccal mucosa. ${ }^{20,22}$ In this study, these lesions were identified in the gingiva and in the alveolar mucosa and presented no gender predilection.

The cases of neurilemmoma presented a predilection for the buccal mucosa although other authors observed it in the lips, ${ }^{2}$ the tongue, the palate ${ }^{19}$ and the mandible. ${ }^{5}$ These most often occurred in children and young adults with a mean age of 23.7 years. Most reports suggested that the majority of tumors arise between 10 and $40^{24,25}$ and between 20 and 50 years of age. ${ }^{11}$ Some studies reported that males and females are equally affected. Shklar, Meyer ${ }^{7}$ (1963) reported a male preponderance while other studies showed a female dominance. ${ }^{24,25}$ In this study, only women were affected.

The unique occurrence of PEN appeared in a white woman whose age was not duly noted. Some authors reported that this entity may develop anywhere on the face of adults, most frequently in the 
$5^{\text {th }}, 6^{\text {th }}$, and $7^{\text {th }}$ decades of life, and that both genders are equally affected. ${ }^{5,10,26}$ PEN rarely appears in the oral cavity, and when it was diagnosed, it occurred more commonly in the palate and maxillary mucosa. ${ }^{10,26}$ This runs in direct contrast with our case, which was found in the buccal mucosa.

Although only three cases of MPNST were observed, it is interesting to note that all occurred in male patients. Enzinger, Weiss ${ }^{2}$ (1995) also reported that more males than females were affected by MPNST. The mean age of 45 years was observed in our study. Other authors reported that this malignant lesion affects, most frequently, patients from 20 to 50 years of age. ${ }^{2}$ The present lesions occurred in the tongue, the palate and the mandible. The cases of this entity have been reported mostly in soft tissues and less commonly in bones. ${ }^{27}$ It can occur in the palate, lips, buccal mucosa, mental foramen,

\section{References}

1. Chrysomali E, Papanicolaou SI, Dekker NP, Regezi JA. Benign neural tumors of the oral cavity: a comparative immunohistochemical study. Oral Surg Oral Med Oral Pathol Oral Radiol Endod. 1997;84(4):381-90.

2. Enzinger FM, Weiss SW. Soft tissue tumors. $3^{\text {rd }}$ ed. St. Louis: Mosby-Year Book; 1995.

3. Argenyi ZB. Immunohistochemical characterization of palisaded, encapsulated neuroma. J Cutan Pathol. 1990;17(6):32935 .

4. Requena L, Sangueza O. Benign neoplasms with neural differentiation: a review. Am J Dermatopathol. 1995;17(1):75-96.

5. Wright BA, Jackson D. Neural tumors of the oral cavity. Oral Surg Oral Med Oral Pathol Oral Radiol Endod. 1980;49(6):509-22.

6. Jones AV, Franklin CD. An analysis of oral and maxillofacial pathology found in adults over a 30-year period. J Oral Pathol Med. 2006;35(7):392-401.

7. Shklar G, Meyer I. Neurogenic tumors of the mouth and jaws. Oral Surg Oral Med Oral Pathol. 1963;9:1075-93.

8. Williams HK, Cannell H, Silvester K, Williams DM. Neurilemmoma of the head and neck. Br J Oral Maxillofac Surg. 1993;31(1):32-5.

9. Tomich CE, Moll MC. Palisaded, encapsulated neuroma of the lip. J Oral Surg. 1976;34(3):265-8.

10. Magnusson B. Palisaded encapsulated neuroma (solitary circumscribed neuroma) of the oral mucosa. Oral Surg Oral Med Oral Pathol Oral Radiol Endod. 1996;82(3):302-4.

11. Pilavaki M, Chourmouzi D, Kiziridou A, Skordalaki A, Zarampouzas T, Dervelengas A. Imaging of peripheral nerve and submandibular triangle. ${ }^{28}$

\section{Conclusions}

This paper provides epidemiological data that can be an important auxiliary in clinical dentistry and oral pathology practice, mainly in the diagnosis of the oral peripheral nerve sheath tumors, which rarely occur in the oral cavity. This study may also be used as a data reference of oral peripheral nerve sheath tumors for other populations.

\section{Acknowledgements}

This study was supported by grants from the National Council for Scientific and Technological Development (CNPq - 484974/2006-8), FAPEMIG (CDS 895/05), and CAPES, Brazil. RA Mesquita and MCF Aguiar are research fellows of CNPq.

sheath tumors with pathologic correlation: pictorial review. Eur J Radiol. 2004;52(3):229-39.

12. Eversole LR, Schwartz DW, Sabes WR. Central and peripheral fibrogenic and neurogenic sarcoma of the oral regions. Oral Surg Oral Med Oral Pathol. 1973;36(1):49-62.

13. Corrêa PH, Nunes LC, Johann AC, Aguiar MC, Gomez RS, Mesquita RA. Prevalence of oral hemangioma, vascular malformation and varix in a Brazilian population. Braz Oral Res. 2007;21(1):40-5.

14. Santos JN, Pinto LP, Figueiredo CR, Souza LB. Odontogenic tumors: analysis of 127 cases. Pesqui Odontol Bras. 2001;15(4):308-13.

15. Hirose T, Tani T, Shimada T, Ishizawa K, Shimada S, Sano T. Immunohistochemical demonstration of EMA/Glut1-positive perineurial cells and CD34-positive fibroblastic cells in peripheral nerve sheath tumors. Mod Pathol. 2003;16(4):293-8.

16. Johnson MD, Glick AD, Davis BW. Immunohistochemical evaluation of Leu-7, myelin basic-protein, S100-protein, glial-fibrillary acidic-protein, and LN3 immunoreactivity in nerve sheath tumors and sarcomas. Arch Pathol Lab Med. 1988;112(2):155-60.

17. Weiss SW, Langloss JM, Enzinger FM. Value of S-100 protein in the diagnosis of soft tissue tumors with particular reference to benign and malignant Schwann cell tumors. Lab Invest. 1983;49(3):299-308.

18. Sist TC, Greene GW. Traumatic neuroma of the oral cavity. Oral Surg Oral Med Oral Pathol. 1981;51(4):394-402.

19. Ellis GL, Abrams AM, Melrose RJ. Intraosseous benign neural sheath neoplasms of the jaws. Report of seven new cases and 
review of the literature. Oral Surg Oral Med Oral Pathol. 1977;44(5):731-43.

20. D'Ambrosio JA, Langlais RP, Young RS. Jaw and skull changes in neurofibromatosis. Oral Surg Oral Med Oral Pathol. 1988;66(3):391-6.

21. Shapiro SD, Abramovitch K, Van Dis ML, Skoczylas LJ, Langlais RP, Jorgenson RJ et al. Neurofibromatosis: oral and radiographic manifestations. Oral Surg Oral Med Oral Pathol. 1984;58(4):493-8.

22. Bongiorno MR, Pistone G, Aricó M. Manifestations of the tongue in neurofibromatosis type I. Oral Dis. 2006;12(2):1259.

23. Baden E, Jones JR, Khedekar R, Burns WA. Neurofibromatosis of the tongue: a light and electron microscopic study with review of the literature from 1849 to 1981. J Oral Med. 1984;39(3):157-64.
24. Cherrick HM, Eversole LR. Benign neural sheath neoplasms of the oral cavity. Report of thirty-seven cases. Oral Surg Oral Med Oral Pathol. 1971;32(6):900-9.

25. Hatziotia JC, Asprides H. Neurilemoma (Schwannoma) of the oral cavity. Oral Surg Oral Med Oral Pathol. 1967;24(4):51026.

26. Chauvin PJ, Wysocki GP, Daley TD, Pringle GA. Palisaded encapsulated neuroma of oral mucosa. Oral Surg Oral Med Oral Pathol. 1992;73(1):71-4.

27. Bullock MJ, Bedard YC, Bell RS, Kandel R. Intraosseous malignant peripheral nerve sheath tumor. Report of a case and review of the literature. Arch Pathol Lab Med. 1995;119(4):367-70.

28. Piatelli A, Angelone A, Pizzicannella G, Piatelli M. Malignant schwannoma of the tongue. Report of a case and review of the literature. Acta Stomatol Belg. 1984;81(3):213-25. 